Portland State University

PDXScholar

10-1-1995

\title{
Doubled CO2 Experiments With the Global Change Research Center Two-Dimensional Statistical Dynamical Climate Model
}

R. M. MacKay

Oregon Graduate Institute of Science and Technology

M. A. K. Khalil

Portland State University, aslamk@pdx.edu

Follow this and additional works at: https://pdxscholar.library.pdx.edu/phy_fac

Part of the Physics Commons

Let us know how access to this document benefits you.

\section{Citation Details}

MacKay, R. M., \& Khalil, M. K. (1995). Doubled CO2 experiments with the Global Change Research Center two-dimensional statistical dynamical climate model. Journal Of Geophysical Research, 100(D10), 21127-21135.

This Article is brought to you for free and open access. It has been accepted for inclusion in Physics Faculty Publications and Presentations by an authorized administrator of PDXScholar. Please contact us if we can make this document more accessible: pdxscholar@pdx.edu. 


\title{
Doubled $\mathrm{CO}_{2}$ experiments with the Global Change Research Center two-dimensional statistical dynamical climate model
}

\author{
R.M. MacKay ${ }^{1}$ and M.A.K. Khalil ${ }^{2}$ \\ Oregon Graduate Institute of Science \& Technology, Global Change Research Center, Portland, Oregon
}

\begin{abstract}
The zonally averaged response of the Global Change Research Center two-dimensional (2-D) statistical dynamical climate model (GCRC 2-D SDCM) to a doubling of atmospheric carbon dioxide ( 350 parts per million by volume (ppmv) to $700 \mathrm{ppmv}$ ) is reported. The model solves the two-dimensional primitive equations in finite difference form (mass continuity, Newton's second law, and the first law of thermodynamics) for the prognostic variables: zonal mean density, zonal mean zonal velocity, zonal mean meridional velocity, and zonal mean temperature on a grid that has 18 nodes in latitude and 9 vertical nodes (plus the surface). The equation of state, $p=\rho R T$, and an assumed hydrostatic atmosphere, $\Delta p=-\rho g \Delta z$, are used to diagnostically calculate the zonal mean pressure and vertical velocity for each grid node, and the moisture balance equation is used to estimate the precipitation rate. The model includes seasonal variations in solar intensity, including the effects of eccentricity, and has observed land and ocean fractions set for each zone. Seasonally varying values of cloud amounts, relative humidity profiles, ozone, and sea ice are all prescribed in the model. Equator to pole ocean heat transport is simulated in the model by turbulent diffusion. The change in global mean annual surface air temperature due to a doubling of atmospheric $\mathrm{CO}_{2}$ in the 2-D model is $1.61 \mathrm{~K}$, which is close to that simulated by the one-dimensional (1-D) radiative convective model (RCM) which is at the heart of the 2-D model radiation code ( $1.67 \mathrm{~K}$ for the moist adiabatic lapse rate assumption in 1-D $\mathrm{RCM})$. We find that the change in temperature structure of the model atmosphere has many of the characteristics common to General Circulation Models, including amplified warming at the poles and the upper tropical troposphere, and stratospheric cooling. Because of the potential importance of atmospheric circulation feedbacks on climate change, we have also investigated the response of the zonal wind field to a doubling of $\mathrm{CO}_{2}$ and have found distinct patterns of change that are related to the change in temperature structure. In addition, we find that both the global mean kinetic energy and simulated Hadley circulation increase when $\mathrm{CO}_{2}$ is doubled. The increase in mean kinetic energy is a result of the increase in upper level meridional temperature gradients simulated by the model. It is stressed that changes in atmospheric dynamics associated with increased carbon dioxide may also be very important to the final steady state distribution of such greenhouse gases as ozone and water vapor. Hence further research in this regard is warranted.
\end{abstract}

\section{Introduction}

Estimating potential climatic changes resulting from variations in atmospheric composition is important not only to scientists and policy makers looking toward the future but also to paleoclimatologists interested in exploring past climates. Over the past 30 years a variety of climate models of varying complexity have been used to explore these changes; for reviews see North et al. [1981] energy balance models (EBMs); Ramanathan and Coakley [1978] one-dimensional radiative convective models (1-D RCMs), Saltzman [1978] two-dimensional statistical dynamical climate models (2-D SDCMs), and Mitchell [1989] general circulation models

\footnotetext{
'Now at Atmospheric and Environmental Research, Inc., Cambridge, Massachusetts.

${ }^{2}$ Now at Portland State University, Physics, Portland, Oregon.

Copyright 1995 by the American Geophysical Union.
}

Paper number 95JD02121.

0148-0227/95/95JD-02121\$05.00
(GCMs). MacKay and Khalil [1994] have recently introduced a 2-D SDCM which has been developed at the Global Change Research Center (GCRC 2-D SDCM). In this paper the steady state response of this model to a doubling of atmospheric carbon dioxide (the $2 \mathrm{xCO}_{2}$ experiment) is explored.

Many groups have performed the $2 \mathrm{xCO}_{2}$ experiment, so performing this experiment offers an easy way to compare the GCRC 2-D SDCM's sensitivity to that of other climate models. We are aware of several other 2-D SDCMs [Saltzman and Vernekar, 1972; Hunt, 1973; Schneider and Lindzen, 1977; Held and Suarez, 1978; Schoeberl and Strobel, 1978; MacCracken and Ghan, 1987; Stone and Yao, 1990], but for most cases, results for doubled $\mathrm{CO}_{2}$ have not been reported. This seems to be true despite the fact that many of these models did have radiation codes that were sophisticated enough to explore their $2 \mathrm{xCO}_{2}$ response. Knowing the response of a 2-D SDCM and comparing it to more advanced GCMs and less sophisticated 1-D radiative convective models (RCMs) can be exceedingly useful in understanding the mechanisms respon- 
sible for a particular climatic response. The importance of potential feedbacks between changes in atmospheric chemical composition, climate change, and atmospheric circulation has been emphasized by Wang et al. [1990]. Thus we not only focus here on the change in the temperature structure of the model atmosphere for the $2 \mathrm{xCO}_{2}$ experiment, but we also follow the investigation of Rosen and Gutowski [1992] and analyze the change in model dynamics resulting from a doubling of $\mathrm{CO}_{2}$. The literature is particularly scarce of 2-D SDCM simulations of perturbations in atmospheric dynamics resulting from $2 \mathrm{xCO}_{2}$.

This paper is divided into four sections. In section 1 a short introduction is given, and in section 2 the model is briefly described. The response of the model to the $2 \mathrm{xCO}_{2}$ experiment (changing the atmospheric $\mathrm{CO}_{2}$ concentration from 350 parts per million by volume (ppmv) to $700 \mathrm{ppmv}$ ) is presented in section 3. Along with the simulated $2 \mathrm{xCO}_{2}$ perturbations in model temperature and zonal wind fields, the change in the model's mean atmospheric kinetic energy is discussed in section 3 and compared to the results of a similar GCM study performed by Branscome and Gutowski [1992]. To conclude the third section, we present the simulated changes in the mass stream function and parameterized eddy momentum flux due to a doubling of atmospheric $\mathrm{CO}_{2}$. The results are summarized in section 4 .

\section{Model Description}

The GCRC 2-D SDCM is described in detail by MacKay [1994] and MacKay and Khalil [1994]. However, for completeness, we outline the fundamental model physics below.

The GCRC 2-D SDCM is essentially a series of vertical 1-D RCMs aligned next to each other. Fluxes of energy, mass, momentum, and moisture can be transferred from one neighboring model grid point to the next or from the surface to the boundary layer. The horizontal resolution of each grid may be varied, but for this work, there are 18 latitude zones of $9.5 \mathrm{deg}$ in latitude $\left(171^{\circ} / 18\right)$. There are nine atmospheric layers and one surface layer.

We use the primitive equations in zonally averaged form to solve for the climatic state of the model planet. The equations are solved as an initial valued problem to obtain the zonal mean values of the prognostic variables temperature, density, meridional velocity, and zonal velocity. The equation of state is used to diagnostically calculate the pressure, and the assumption of hydrostatic equilibrium, the equation of state, and the continuity equation are all used to diagnostically determine the vertical velocity.

Seasonally varying cloud amounts, relative humidity, ozone distribution, sea ice area coverage and thickness, surface albedo, and snow cover are all prescribed in the model and do not vary from year to year. Fractional ocean and land areas are set for each zone. The daily average flux of incident solar radiation per unit surface area, $Q_{s}$, for each zone is calculated following Liou [1980], and a diurnal average solar zenith angle is calculated from $Q_{s}$ and the number of daylight hours. Variations in solar intensity at the top of the atmosphere due to the Earth's eccentricity are also included.

For the simulations described in this work, the Earth's surface is assumed to consist of land, a mixed layer ocean of depth $50.0 \mathrm{~m}$, and sea ice. All Earth-based surfaces are assumed to have an infrared emissivity of 1.0. The fourth power of the ef- fective radiating temperature of the Earth's surface, which is used for calculating the upward flux of IR radiation received by the atmosphere, is taken as the area weighted average of the surface temperatures to the fourth power. Zonal mixing of energy in the atmosphere is assumed to be instantaneous, making the air temperature of a zone independent of longitude. Meridional heat transport in the ocean mixed-layer is assumed to be via turbulent diffusion, which depends on the meridional temperature gradient of the mixed layer temperature.

The parameterization schemes of Yao and Stone [1987], and Stone and Yao [1987, 1990] are used to estimate the meridional flux of zonal momentum, $\overline{u^{\prime} v^{\prime}}$, the meridional flux of sensible heat, $\overline{v^{\prime} T^{\prime}}$, and the vertical flux of eddy heat energy, $\overline{w^{\prime} \theta^{\prime}}$. As described by MacKay and Khalil [1994], we have modified the above parameterization schemes slightly to help improve our model's performance at simulating the observed climate. As noted and described in MacKay [1994], $\overline{u^{\prime} w^{\prime}}$ and $\overline{v^{\prime} w^{\prime}}$ are simulated using vertical mixing length theory.

We use a lapse rate adjustment scheme, similar to that described by Stone and Carlson [1979] which is based on baroclinic stability. The critical lapse rate is set equal to either the moist adiabatic lapse rate or the critical lapse rate calculated from baroclinic stability theory (with a lower limit of $4 \mathrm{~K} / \mathrm{km}$ for high latitudes). We use a convective adjustment similar to Manabe and Wetherald's [1967] to force the atmospheric lapse rate to be less than the smaller of the two calculated lapse rates. The vertical convective scheme is similar to that described in Lindzen et al. [1982] for moist convection in that a drag law is used to exchange latent and sensible heat between the surface and the boundary layer, and then only the atmospheric layers undergo an internal convective adjustment.

The heart of our two-dimensional model is the one-dimensional radiative convective model (1-D RCM) described in detail by MacKay and Khalil [1991]. The modifications that we have made to it are described completely by MacKay and Khalil [1994]. We have included the atmospheric absorption of solar radiation due to $\mathrm{H}_{2} \mathrm{O}, \mathrm{O}_{3}, \mathrm{O}_{2}$, and $\mathrm{CO}_{2}$ for both clear and cloudy conditions, as well as the atmospheric absorption of terrestrial radiation due to $\mathrm{H}_{2} \mathrm{O}, \mathrm{CO}_{2}, \mathrm{O}_{3}, \mathrm{~N}_{2} \mathrm{O}, \mathrm{CH}_{4}, \mathrm{CFC}$ 11 , and $\mathrm{CFC}-12$. We follow the treatment described by Stephens [1984] for the calculation of radiative fluxes in regions of multiple cloud. In regions of the sky that have both cloud and gas infrared emissivities $\left(\varepsilon_{\mathrm{c}}\right.$ and $\left.\varepsilon_{\mathrm{g}}\right)$ the total emissivity $\varepsilon$ is given by

$$
\varepsilon=1.0-\left(1-\varepsilon_{g}\right)\left(1-\varepsilon_{c}\right)
$$

In regions of the sky that have several layers of cloud above, we assume that the cloud layers overlap randomly and that the total cloud cover can be written as

$A_{T}=1-\left(1-A_{1}\right)\left(1-A_{2}\right) \ldots \ldots$.

where $A_{i}$ represents the amount of the sky covered by the ith cloud.

Tuning of the model is performed by tuning the cloud optical depth due to cloud droplets (absorption by water vapor in the cloud is calculated from $k$ distribution theory) or by adjusting the meridional heat transport in the ocean. As explained by MacKay and Khalil [1994], there is also an additional term added to the meridional heat transport parameterization of Stone and Yao [1990] which prevents model instabilities resulting from excessively low polar temperatures in the winter upper atmosphere.

To ensure steady state conditions, all model runs shown here were 24 years in length. A student t-test is used to 
estimate the error in model output associated with the interannual variability in the model. A 5-year running average of the seasonal mean of each model grid point is taken. For each grid point, an estimate $s$ of the variance in grid point seasonal mean temperature, $T_{i, j}$, is calculated according to

$$
s_{i, j}(k)=\frac{1}{4} \sum_{t=-2}^{2}\left(T_{i, j}(k+t)-\overline{T_{i, j}(k)}{ }_{5}\right)
$$

where $i, j$ denote the grid point location, $k$ is the center of the 5 -year mean (for a 24-year run, 5 -year mean, $k=3$ to 22 , and there are 4 degrees of freedom). The maximum value of $s$ over all grid points, $s_{\max }$, is then calculated to estimate the maximum model error, which at the $95 \%$ confidence level is $1.23 s_{\max }$. The values of $s_{\max }$ for temperature, zonal velocity, eddy momentum flux, and mass stream function are listed in Table 1 for the $1 \mathrm{xCO}_{2}$ and $2 \mathrm{xCO}_{2}$ runs described in section 3 . Since $s$ varies slightly from year to year, even at the end of the 24-year run, the values in Table 1 are the largest values obtained from years 18 through 22 . The model precisions listed in Table 1 are given to help indicate the internal variability of the model and are in no way meant to represent model accuracy. It is worth noting here that for very precise perturbation studies, the 1-D RCM (simulating the global mean conditions with annual mean radiation) has the advantage in that it has very small day-to-day variability at steady state and is also much faster computationally. However, what is gained in precision and speed is lost in the ability to realistically simulate additional physical processes.

\section{The $2 \mathrm{xCO}_{2}$ Experiment}

\subsection{Temperature Changes}

Figure 1 shows the zonal mean surface air temperature $(z=$ $100 \mathrm{~m}$ ) of the model control run for annual, summer (JJA), and winter (DJF) averages. The global average annual mean surface air temperature is $287.10 \mathrm{~K}$. All model outputs of the control run $\left(1 \mathrm{xCO}_{2}\right)$ for the experiments presented here are in very good qualitative agreement with the control run presented by MacKay and Khalil [1994]. In Figure 2, the simulated latitudinal and seasonal response of zonal surface air temperature for the $2 \mathrm{xCO}_{2}$ experiment (changing the $\mathrm{CO}_{2}$ concentration from $350 \mathrm{ppmv}$ to $700 \mathrm{ppmv}$ ) is shown. For the annual mean simulation, the model is consistent with the results of others in that the higher latitudes experience more warming than the lower latitudes (see for example Schlesinger and Mitchell [1987] or Held [1993]). In their review of the response of climate models to changes in $\mathrm{CO}_{2}$, Schlesinger and Mitchell [1987] note this similarity in the predictions of general circulation models (GCMs). They attribute this preferential warming at high-latitudes to the ice albedo feedback, changes in snow cover, and changes in sea ice

Table 1. Model Interannual Variability, $s_{\max }, 1 \mathrm{xCO}_{2}$ $\left(2 \mathrm{xCO}_{2}\right)$

\begin{tabular}{lllll}
\hline & JJA & DJF \\
\hline Temperature $(\mathrm{K})$ & 0.02 & $(0.1)$ & 0.01 & $(0.01)$ \\
Zonal Velocity $(\mathrm{m} / \mathrm{s})$ & 0.05 & $(0.10)$ & 0.01 & $(0.02)$ \\
$\mathrm{U}^{\prime} \mathrm{V}^{\prime}$ Flux $\left(\mathrm{m}^{2} / \mathrm{s}^{2}\right)$ & 0.3 & $(0.3)$ & 0.1 & $(0.1)$ \\
Mass Stream & 0.01 & $(0.02)$ & 0.01 & $(0.01)$ \\
Function $(10 \mathrm{Tg} / \mathrm{s})$ & & & & \\
\hline
\end{tabular}

Values given to one significant figure.
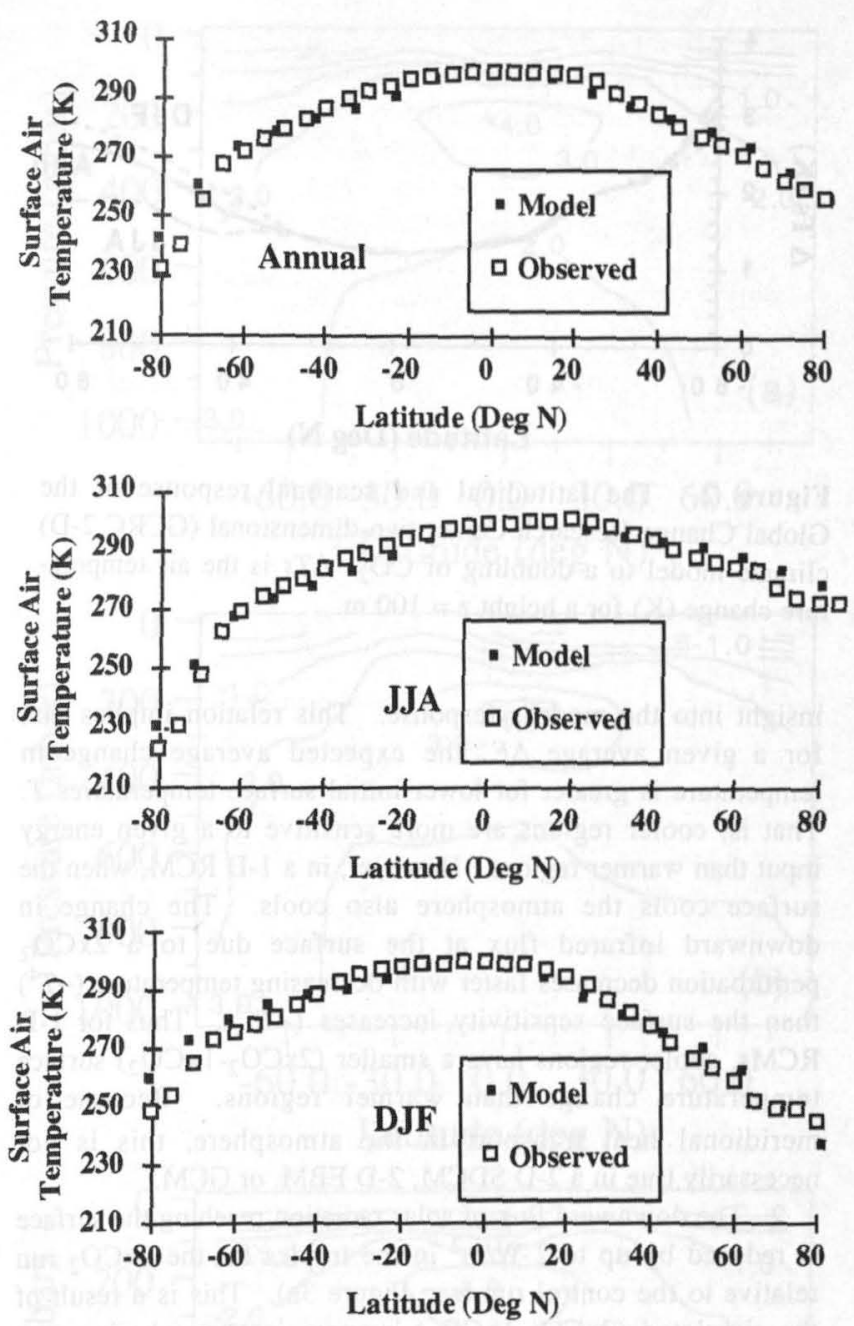

Figure 1. Control run for the zonal-mean annual, summer (JJA), and winter (DJF) surface air temperature. Observations are from National Center for Atmospheric Research (NCAR), Data Support Section, Scientific Computing Division. Model values are for $z=100 \mathrm{~m}$.

thickness. They also note that high-latitude warming is particularly strong during winter. The simulation of these processes has been intentionally suppressed in our model and hence other processes are responsible for this preferential high-latitude warming predicted by our model.

Our analysis of model diagnostics and results of experiments with the 1-D RCM (used in the 2-D model) have identified five processes responsible for the $2 \mathrm{xCO}_{2}$ warming simulated by our model being greater at high latitudes than in the tropics. To clarify these processes, we provide a short summary of our analysis here.

1. Since changes in surface air temperature are strongly coupled to changes in surface temperature, it is worth looking at the equilibrium relation between a small change in energy flux $\Delta E$ and the small change in surface temperature $\Delta T$ $\left(\Delta T=\Delta E /\left(4 \sigma T^{3}\right)\right.$, where $\sigma$ is the Stefan-Boltzman constant. For our model, the change in surface energy may be from changes in solar or terrestrial radiative fluxes, changes in latent or sensible heat fluxes from the surface, or a change in the meridional heat transport in the ocean. Since in our model $\Delta E$ is continually changing, few locations in the model ever really fit this relation very well, but it does provide some 


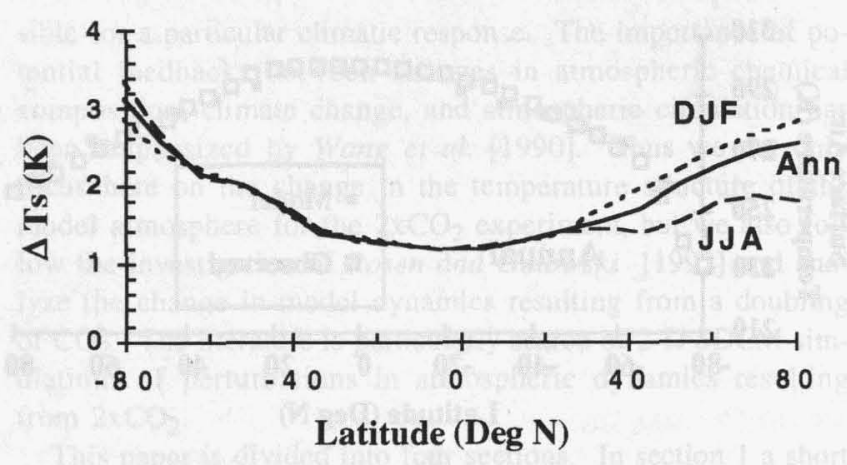

Figure 2. The latitudinal and seasonal response of the Global Change Research Center two-dimensional (GCRC 2-D) climate model to a doubling of $\mathrm{CO}_{2} . \Delta T s$ is the air temperature change $(\mathrm{K})$ for a height $\mathrm{z}=100 \mathrm{~m}$.

insight into the model's response. This relation implies that for a given average $\Delta E$, the expected average change in temperature is greater for lower initial surface temperatures $T$. That is, cooler regions are more sensitive to a given energy input than warmer regions. However, in a 1-D RCM, when the surface cools the atmosphere also cools. The change in downward infrared flux at the surface due to a $2 \mathrm{xCO}_{2}$ perturbation decreases faster with decreasing temperature $\left(\sim T^{4}\right)$ than the surface sensitivity increases $\left(\sim T^{-3}\right)$. Thus for 1-D RCMs, cooler regions have a smaller $\left(2 \mathrm{xCO}_{2}-1 \mathrm{xCO}_{2}\right)$ surface temperature change than warmer regions. Because of meridional heat transport in the atmosphere, this is not necessarily true in a 2-D SDCM, 2-D EBM, or GCM.

2. The downward flux of solar radiation reaching the surface is reduced by up to $2 \mathrm{~W} / \mathrm{m}^{2}$ in the tropics for the $2 \mathrm{xCO}_{2}$ run relative to the control run (see Figure $3 \mathrm{a}$ ). This is a result of the simulated $\left(2 \mathrm{xCO}_{2}-1 \times \mathrm{CO}_{2}\right)$ increase in atmospheric water vapor, which is an absorber of near infrared solar radiation. Of course, there is no change in the downward flux of solar radiation reaching the surface in the polar regions during winter, and hence this negative feedback has no influence near the poles during winter.

3. The static stability (lack of convection from the surface) of the polar atmosphere (northern hemisphere winter and southern hemisphere year round) focuses the $2 \mathrm{xCO}_{2}$ warming to the lowest layers of the atmosphere for these locations. This effect can be mimicked somewhat by a 1-D RCM by allowing no convection to take place, although the 2-D SDCM (or EBM) structure allows for horizontal energy transport into the upper layers of the atmosphere, resulting in a larger $\left(2 \times \mathrm{CO}_{2}-1 \times \mathrm{CO}_{2}\right)$ surface forcing than would exist for a 1-D RCM in pure radiative equilibrium. Ramanathan [1977] attributes this explanation of large surface warming in the stable polar atmosphere to Wetherald and Manabe [1975].

4. The $\left(2 \mathrm{xCO}_{2}-1 \mathrm{xCO}_{2}\right)$ increase in downwelling flux of thermal radiation at the surface, $\Delta F$, is minimum in the tropics $\left(\sim 9 \mathrm{~W} / \mathrm{m}^{2}\right)$ compared with $>15 \mathrm{~W} / \mathrm{m}^{2}$ at high latitudes during winter (see Figure 3b). Ramanathan [1977] offered a partial explanation for this minimum in $\Delta F$ simulated by our model. Ramanathan showed that a change in lapse rate $(-d T / d z)$ can have a feedback (positive or negative) on the actual steady state change in surface temperature. In regions of the atmosphere where the $\left(2 \mathrm{xCO}_{2}-1 \mathrm{xCO}_{2}\right)$ lapse rate decreases, the feedback is negative. Simply stated, as the lapse rate decreases, the $\left(2 \mathrm{xCO}_{2}-1 \mathrm{xCO}_{2}\right)$ tropospheric warming is dis- tributed to higher levels of the atmosphere, and the surface ex periences a smaller change in temperature than it does with fixed lapse rate. The opposite is true (positive feedback) in a statically stable atmosphere which allows for a $\left(2 \mathrm{xCO}_{2}\right.$ $1 \mathrm{xCO}_{2}$ ) lapse rate increase. For our model, the zero lapse rate feedback latitude is located at approximately 50 deg latitude for each winter hemisphere. The negative lapse rate feedback in the tropics can be easily demonstrated with the 1-D RCM (used in the 2-D SDCM). Using the 1-D RCM to simulate tropical conditions, $\Delta F=14.9 \mathrm{~W} / \mathrm{m}^{2}$ (fixed moist adiabatic lapse rate of $1 \mathrm{xCO}_{2}$ run for $2 \mathrm{xCO}_{2}-1 \times \mathrm{XO}_{2}$ experiment) and $12.1 \mathrm{~W} / \mathrm{m}^{2}$ (variable moist adiabatic lapse rate). Thus we estimate that the lapse rate feedback reduces surface forcing by about $2.8 \mathrm{~W} / \mathrm{m}^{2}$ in the tropics. This reduction of $\Delta F$ is not large enough to get us down to the $\Delta F$ of $9 \mathrm{~W} / \mathrm{m}^{2}$ actually simulated by the 2-D model. We attribute this additional $\sim 3 \mathrm{~W} / \mathrm{m}^{2}$ decrease in $\Delta F$ simulated in the tropics to the enhanced meridional heat transport out of the tropical air mass column. lower mean column temperature will result in a reduction of the downwelling flux of thermal radiation at the surface. There is an accompanying increase in $\Delta \mathrm{F}$ due to enhanced meridional heat transport into the air mass column of the extratropics during the winter of both hemispheres. The seasonal variations in $\Delta F$ are due to seasonal variations in lapse rate change and meridional heat transport from the tropics to extratropics. Also, because of the larger percentage of land in the northern hemisphere, it experiences larger interseasonal variations of $\left(2 \mathrm{xCO}_{2}-1 \times \mathrm{CO}_{2}\right)$ changes in temperature, meridional eddy heat transport, Hadley circulation, and zonal velocity.

5. Other dynamical effects are also partially responsible for the lower climate sensitivity of the tropics simulated by our 2 $\mathrm{D}$ model. There is a small systematic $\left(2 \mathrm{xCO}_{2}-1 \mathrm{xCO}_{2}\right)$ increase in convective cooling in the tropics of between 0.5 and 1 $\mathrm{W} / \mathrm{m}^{2}$, resulting in reduced tropical surface warming in the $2 \mathrm{xCO}_{2}$ environment. Also, during JJA at high latitudes in the northern hemisphere, there is an increase in convective cooling of 1 to $2 \mathrm{~W} / \mathrm{m}^{2}$, explaining some of the interseasonal
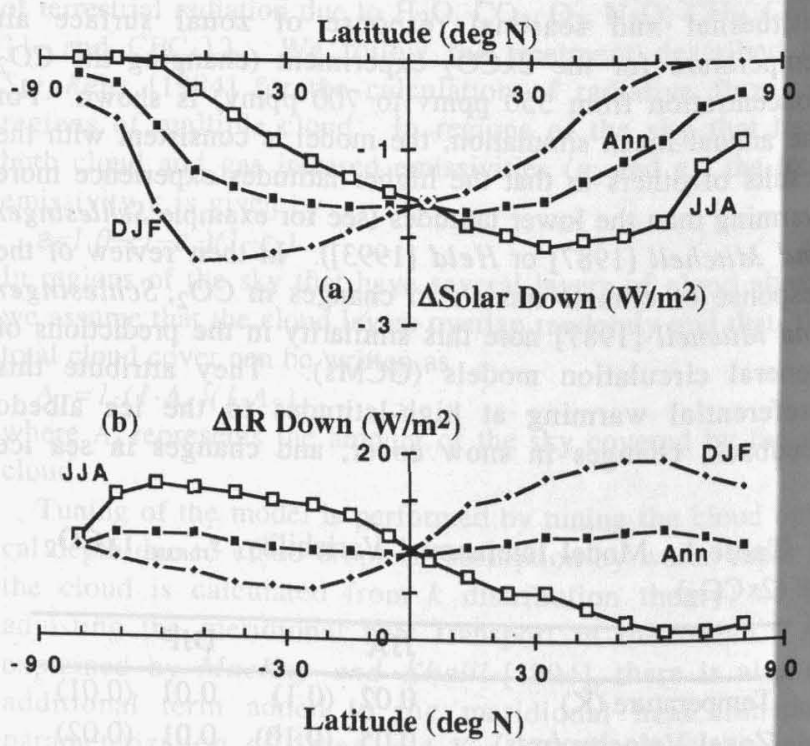

Figure 3. The $\left(2 \mathrm{xCO}_{2}-1 \times \mathrm{CO}_{2}\right)$ changes in (a) downwelling solar flux and (b) thermal flux reaching the surface. Curves are June, July, August (JJA), December, January, February (DJF), and annual means 
difference observed in the northern hemisphere. Near the surface, reduced meridional heat transport from low to high latitudes, resulting from smaller near-surface meridional temperature gradients in both the ocean and the atmosphere, provides a negative feedback which limits the warming at high latitudes.

In Figure 4 , we show the $\left(2 \mathrm{xCO}_{2}-1 \times \mathrm{xO}_{2}\right)$ change in global average surface air temperature, $\Delta T_{s}$, predicted by our model as a function of time using global means from the last 5 years of each run. Comparing Figure 4 with Figure 2, we see that the annual cycle of $\Delta T_{S}$ is primarily driven by seasonal variations in the northern hemisphere. The change in global mean surface $(z=100 \mathrm{~m})$ air temperatures are $1.53 \mathrm{~K}(\mathrm{JJA}), 1.66 \mathrm{~K}$ (DJF), and $1.61 \mathrm{~K}$ (annual). These results are slightly larger than those reported by MacKay [1994], as we have since corrected an error that was present in the original model code for critical lapse rate in the tropics. This error resulted in an enhanced negative lapse rate feedback. Our model's climate sensitivity is low compared to the range of $\Delta T_{s}$ between +1.5 $\mathrm{K}$ and $+4.5 \mathrm{~K}$ with a "best guess" of $2.5 \mathrm{~K}$ reported by The Intergovernmental Panel on Climate Control [1990] for the climate sensitivity of most GCMs for a doubling of $\mathrm{CO}_{2}$. This is expected, since we have suppressed all feedbacks associated with surface albedo, snow cover, and sea ice changes in the simulations presented here.

It is noteworthy that Wang et al. [1990] suggest that including latitude-dependent effects into 2-D models can indeed make their global mean surface temperature less sensitive to trace gas variations than their $1-D$ radiative convective model counterparts. This is true with our 2-D model in that it is about $25 \%$ less sensitive than its basic 1-D RCM (when using the fixed $6.5 \mathrm{~K} / \mathrm{km}$ lapse rate adjustment in the 1-D RCM). Interestingly, when the moist adiabatic lapse rate adjustment is used to represent global mean conditions for the 1-D RCM, the 1-D RCM and 2-D SDCM global mean annual average $\left(2 \mathrm{xCO}_{2}-1 \times \mathrm{xO}_{2}\right)$ temperature changes are very close: $1.67 \mathrm{~K}$ (1-D) and $1.61 \mathrm{~K}(2-\mathrm{D})$.

The simulated $\left(2 \times \mathrm{CO}_{2}-1 \times \mathrm{CO}_{2}\right)$ changes of the zonal mean two-dimensional temperature field are shown in Figure 5 for annual, JJA, and DJF means. Held [1993] gave a review of climate models, which included a brief description of their general sensitivity to doubled carbon dioxide. Our results have several features in common with Held's qualitative interpretation of what GCMs predict for changes in the temperature field due to a doubling of atmospheric $\mathrm{CO}_{2}$. As noted previously, the $\left(2 \mathrm{xCO}_{2}-1 \times \mathrm{CO}_{2}\right)$ surface warming increases as the latitude increases toward the poles in both hemispheres (most notably in the winter season). Also, there

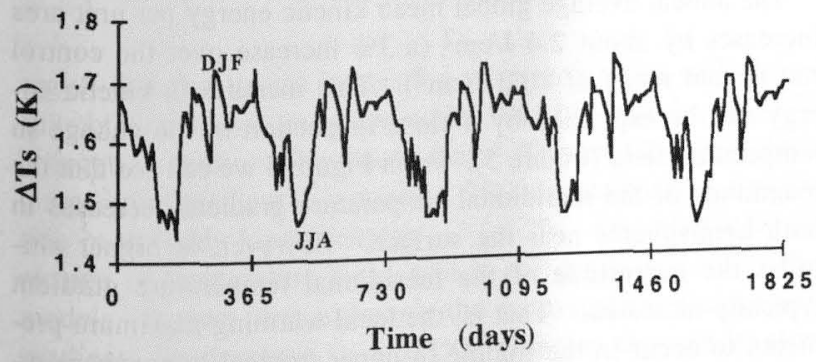

Figure 4. Five-year time series (years 19 through 24) of the simulated change in global mean surface air temperature, $\Delta T_{S}$, due to a doubling of $\mathrm{CO}_{2}$. March 1 is day one.
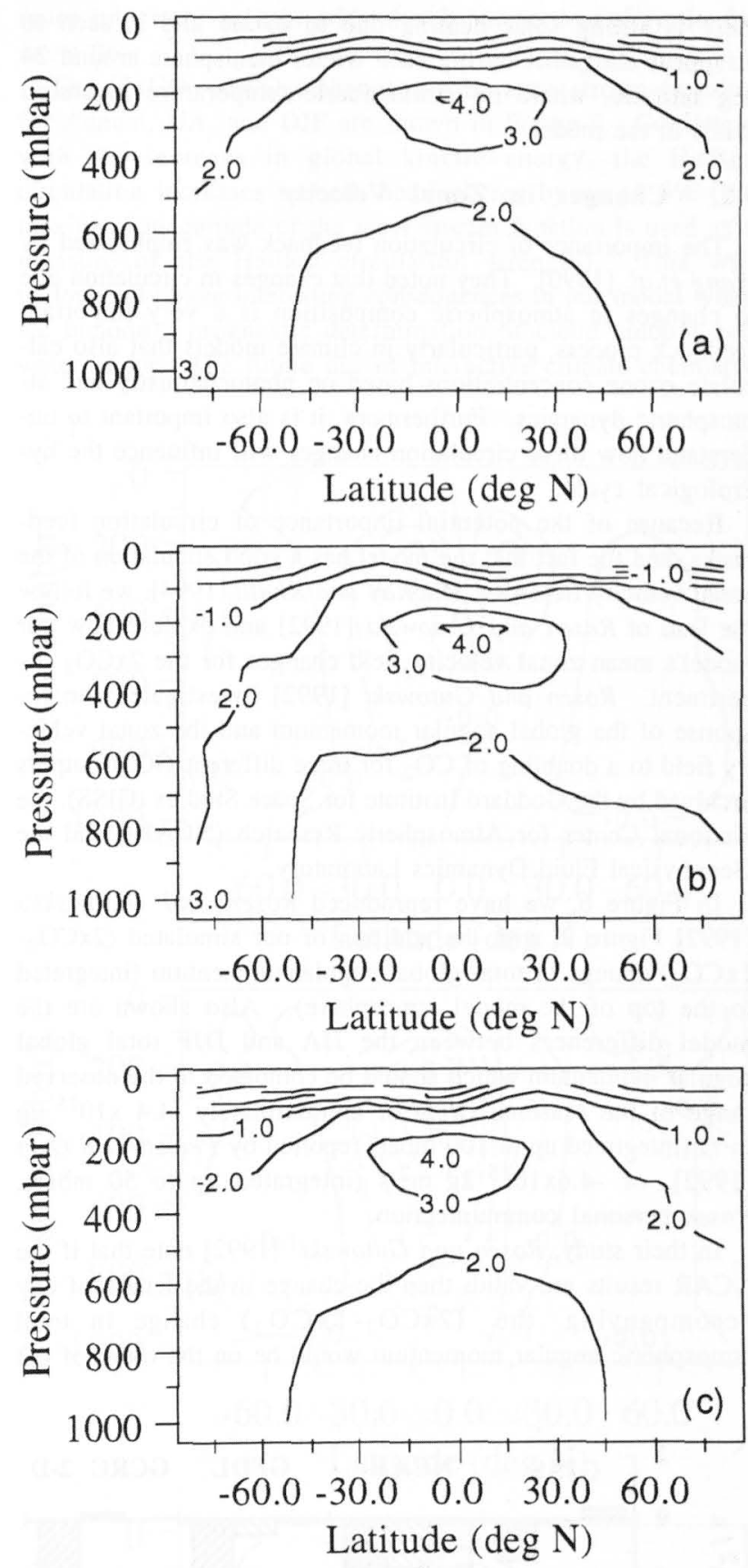

Figure 5. The two-dimensional change in the zonal mean temperature field predicted by the GCRC 2-D climate model for (a) annual, (b) JJA, and (c) DJF averages. (Contour interval is $1.0 \mathrm{~K}$.)

is a local maximum in temperature change predicted to occur in the middle to upper tropical troposphere. Held [1993] attributes this local warming maximum in the upper tropical troposphere, simulated by many climate models, to an increase in the vertical transport of latent heat energy in the tropics due to surface warming. The decrease in the tropical lapse rate calculated by our model simulates this increased vertical transport. Finally, as with most climate models, we have stratospheric cooling. Because of poor model resolution of the stratosphere, the maximum stratospheric cooling is 3.5 to $4 \mathrm{~K}$ in the summer polar stratosphere. The $\left(2 \mathrm{xCO}_{2}-1 \mathrm{xCO}_{2}\right)$ stratospheric cooling effect is strongest during summer when 
there is strong solar heating due to ozone and is seen to disappear altogether during each winter hemisphere around 24 deg latitude, where no stratospheric temperature inversion exists in the model.

\subsection{Changes in Zonal Velocity}

The importance of circulation feedback was emphasized by Wang et al. [1990]. They noted that changes in circulation due to changes in atmospheric composition is a very important feedback process, particularly in climate models that also calculate ozone concentrations based on photochemistry and atmospheric dynamics. Furthermore, it is also important to understand how these circulation changes will influence the hydrological cycle.

Because of the potential importance of circulation feedbacks, and the fact that the model has a good simulation of the zonal velocity field [see MacKay and Khalil, 1994], we follow the lead of Rosen and Gutowski [1992] and explore how our model's mean zonal velocity field changes for the $2 \mathrm{xCO}_{2}$ experiment. Rosen and Gutowski [1992] investigated the response of the global angular momentum and the zonal velocity field to a doubling of $\mathrm{CO}_{2}$ for three different GCM outputs archived by the Goddard Institute for Space Studies (GISS), the National Center for Atmospheric Research (NCAR), and the Geophysical Fluid Dynamics Laboratory.

In Figure 6, we have reproduced Rosen and Gutowski's [1992] Figure 2, with the addition of our simulated $\left(2 \mathrm{xCO}_{2}\right.$ $1 \mathrm{xCO}_{2}$ ) change in total global angular momentum (integrated to the top of the model atmosphere). Also shown are the model differences between the JJA and DJF total global angular momentum which should be compared to the observed range of the seasonal cycle of approximately $-4.4 \times 10^{25} \mathrm{~kg}$ $\mathrm{m}^{2} / \mathrm{s}$ (integrated up to $100 \mathrm{mbar}$ ) reported by Peixoto and Oort [1992], or $-4.6 \times 10^{25} \mathrm{~kg} \mathrm{~m}^{2} / \mathrm{s}$ (integrated up to $50 \mathrm{mbar}$ ), Rosen personal communication.

In their study, Rosen and Gutowski [1992] note that if the NCAR results are valid, then the change in the length of day accompanying the $\left(2 \mathrm{xCO}_{2}-1 \mathrm{xCO}_{2}\right)$ change in total atmospheric angular momentum would be on the order of 0.3

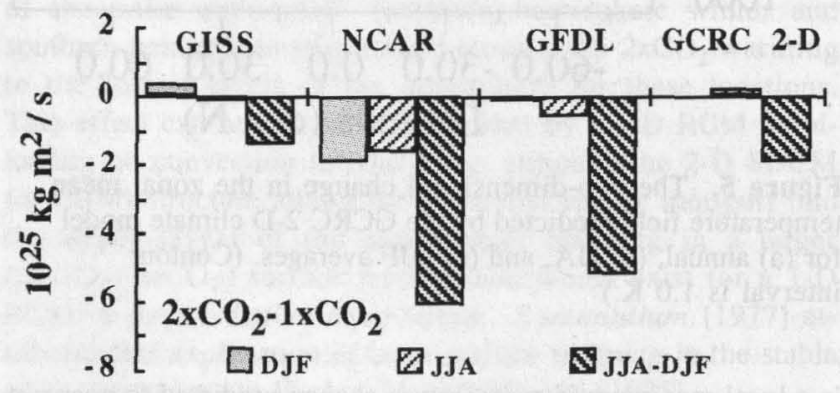

Figure 6. Differences in total global angular momentum $\left(2 \mathrm{XO}_{2}-1 \mathrm{xCO}_{2}\right)$ predicted by each model for JJA and DJF averages, along with JJA minus DJF determined from control runs of each model (from surface to top of model atmosphere). The observed 1981-1994 JJA-DJF angular momentum difference integrated up to $50 \mathrm{mbar}$ is $-4.6 \times 10^{25} \mathrm{~kg} \mathrm{~m} / \mathrm{s}$ with a standard deviation of this difference of $1.4 \times 10^{25} \mathrm{~kg} \mathrm{~m} / \mathrm{s}$ (R.D. Rosen, personal communication, 1994). GISS, Goddard Institute for Space Studies; NCAR, National Center for Atmospheric Research; GFDL, Geophysical Fluid Dynamics Laboratory; GCRC, Global Change Research Center. ms. This is detectable with modern instrumentation and hence could possibly be used as a fingerprint of climate change. Their estimate is based on the conservation of the angular momentum of the solid earth-atmosphere system and an assumed moment of inertia of the solid earth. Rosen et al. [1990] give

$$
\Delta l . o . d .=1.68 \times 10^{-29} \Delta M
$$

for the relationship between the change in length of day and change in total angular momentum, $\Delta M$, of the atmosphere.

In our model, we have a very small change in total global angular momentum at all times of year. Hence our model predicts that the change in length of day will be insignificant. This is likely due to the fact that we have neglected orography in our present model. Hence there is a relatively weak coupling between the atmosphere and surface, making it difficult to have a net transfer of angular momentum between them. do not rule out the possibility of a measurable change in the length of day due to an increase in greenhouse gases.

Rosen and Gutowski [1992] are very conservative about drawing any concrete conclusions regarding the consistent response of the GCM's zonal wind fields to a doubling of $\mathrm{CO}_{2}$. They do say however that "... only in JJA are the patterns of the tropical wind field response similar enough locally to yield significant correlation coefficients among the three models, and yet even these coefficients are not impressively high" (p. 1402). The $\left(2 \mathrm{xCO}_{2}-1 \mathrm{xCO}_{2}\right)$ changes in zonal mean zonal velocity for annual, JJA, and DJF averages, as simulated by our 2-D SDCM, are shown in Figure 7. In all cases, we find very distinct patterns of change predicted by our model: (1) an increase in tropical easterlies $(\Delta u<0)$, (2) an increased westerly flow in the midlatitude to high-latitude regions, and (3) increased westerly flow in the tropical upper atmosphere. It is also interesting to note that the change in tropospheric angular momentum, integrated up to $200 \mathrm{mbar}$, simulated by our model is negative, $-0.43 \times 10^{25} \mathrm{~kg} \mathrm{~m}^{2} / \mathrm{s}$ and $-0.29 \times 10^{2.5}$ $\mathrm{kg} \mathrm{m} / \mathrm{s}$ for DJF and JJA respectively. This result is consistent with the three GCMs analyzed by Rosen and Gutowski [1992], see their Figure 1, and thus appears to be a strong signature of double carbon dioxide simulations. discuss the causes of these patterns of change in more detail below.

\subsection{Other Changes for $2 \mathrm{xCO}_{2}$}

To gain further insight into the model's sensitivity to the doubling of atmospheric carbon dioxide, it is interesting to look at the corresponding changes in other variables of the model, such as global kinetic energy, the field of meridional temperature gradient, mass stream function, and parameterized zonal mean eddy momentum flux, $\overline{u^{\prime} v^{\prime}}$.

The annual average global mean kinetic energy per unit area increases by about $2.4 \mathrm{~J} / \mathrm{cm}^{2}$ (a $3 \%$ increase over the control run annual mean of $80.0 \mathrm{~J} / \mathrm{cm}^{2}$ ). This increase in kinetic energy can be explained by a close inspection of the change in temperature field (Figure 5). From Figure 5 we can see that the magnitude of the meridional temperature gradient decreases in both hemispheres near the surface. However, at higher altitudes the magnitude of the meridional temperature gradien typically increases. That is, the local warming maximum pre dicted to occur in the middle to upper tropical troposphere re sults in an upper level temperature gradient increase. The creased temperature gradients of the middle to upper atmosphere result in an increase of model mean global kinetic 

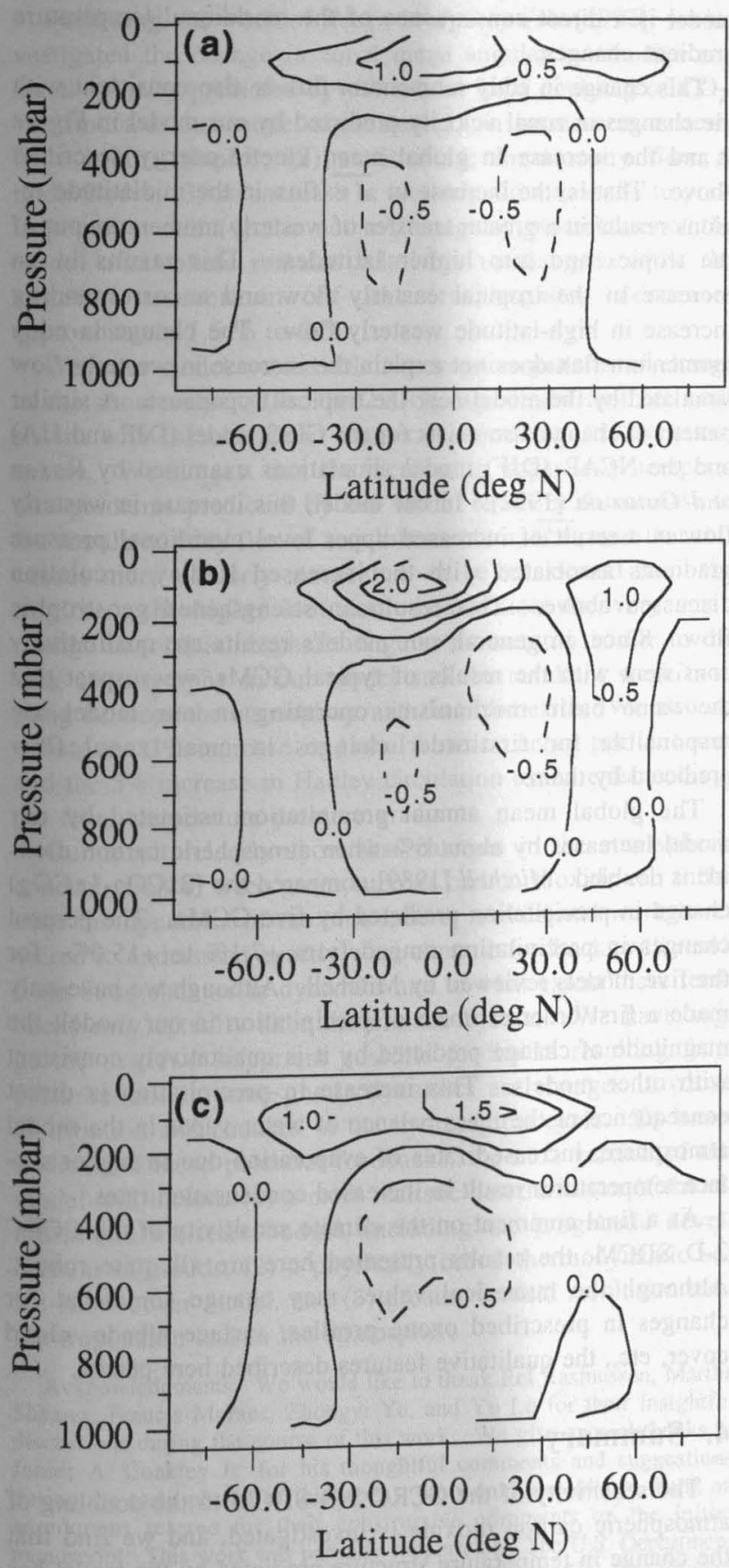

Figure 7. Differences in zonal velocity resulting from the $2 \mathrm{xCO}_{2}$ experiment predicted by the GCRC 2-D model for (a) annual, (b) JJA, (c) and DJF conditions. Contour interval is $0.5 \mathrm{~m} / \mathrm{s}$, and dashed contours are less than zero.

ergy. Our results are interesting when compared with the results of Branscome and Gutowski [1992] for their doubled $\mathrm{CO}_{2}$ energetics study. They note that "The smaller meridional temperature gradient in a doubled $\mathrm{CO}_{2}$ climate leads to a reduction in the eddy kinetic energy ..." (p. 29). Our results for the change in temperature field, which are consistent with other models, suggest that although the near-surface temperature gradients do decrease in a $2 \mathrm{xCO}_{2}$ climate, the temperature gradients of the middle to upper atmosphere actually increase. The two results are not necessarily contradictory, since the temperature gradients in the lower atmosphere may play a more important role in eddy development than they do for mean flow.

The $\left(2 \mathrm{xCO}_{2}-1 \mathrm{xCO}_{2}\right)$ changes in the mass stream function for Annual, JJA, and DJF are shown in Figure 8. Consistent with the increase in global kinetic energy, the Hadley circulation increases in both hemispheres by up to $5 \%$ (the maximum magnitude of the mass stream function is used as a measure of the Hadley circulation strength). This will undoubtedly have interesting consequences in our model when we include a prognostic determination of cloud amount and water vapor. The future use of interactive climate chemistry
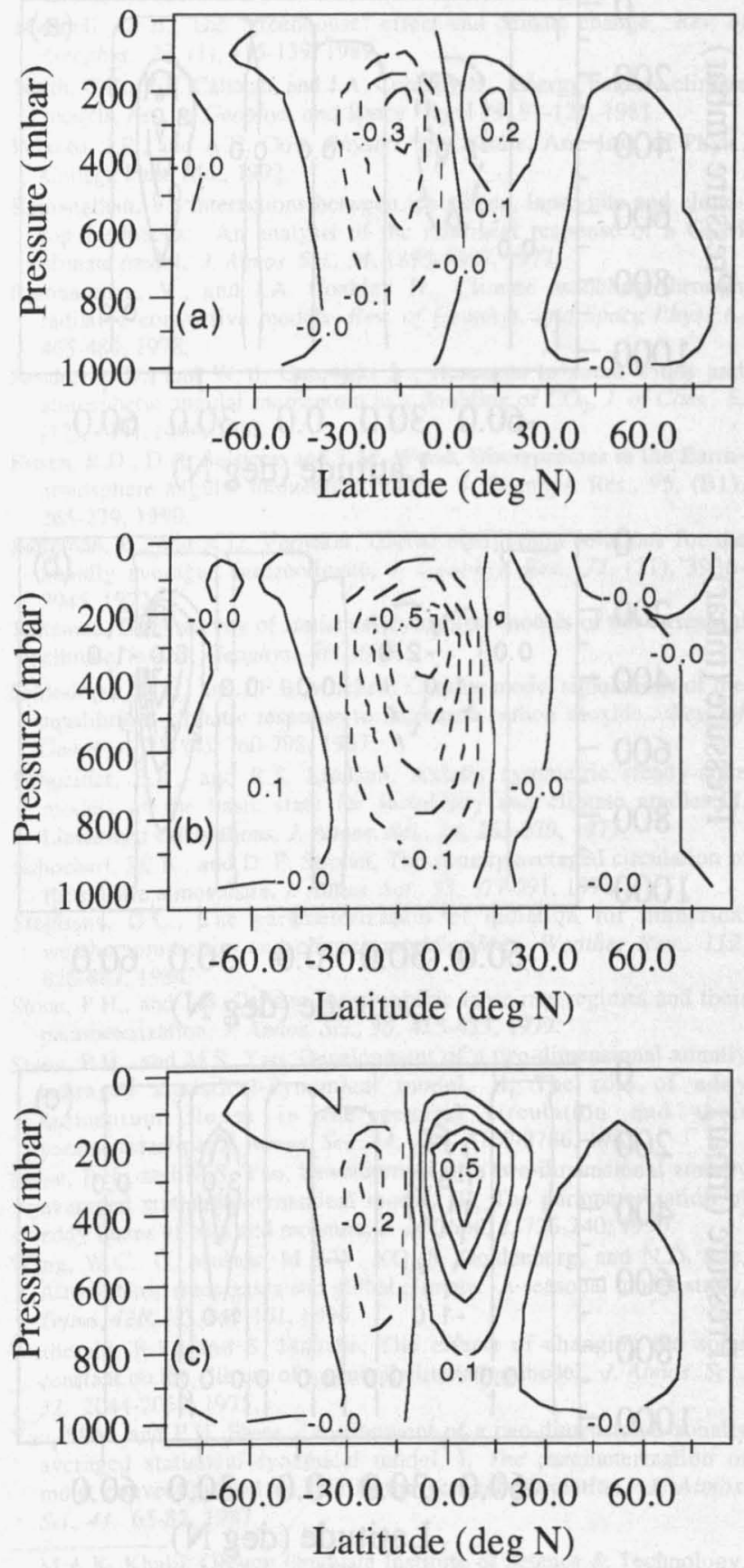

Figure 8. The change in the zonal mean mass stream function $\left(2 \mathrm{xCO}_{2}-1 \times \mathrm{XO}_{2}\right)$ predicted by the GCRC 2-D model for (a) annual, (b) JJA, and (c) DJF averages. Units are 10 $\mathrm{Tg} / \mathrm{s}$, and contour interval is 0.1 . 
models to study the feedbacks between atmospheric dynamics, chemistry (especially ozone distribution), and climate will also be particularly informative.

In Figure 9 , the $\left(2 \mathrm{xCO}_{2}-1 \mathrm{xCO}_{2}\right)$ changes in the seasonal mean parameterized eddy flux of zonal momentum $\left(\overline{u^{\prime} v^{\prime}}\right)$ predicted by our model are shown for annual, JJA, and DJF means. In both hemispheres, the magnitude of the poleward flux of westerly momentum increases in the midlatitude regions. Since the parameterized eddy momentum flux is highly dependent upon the temperature gradient, this increase in the meridional transport of eddy momentum predicted by our
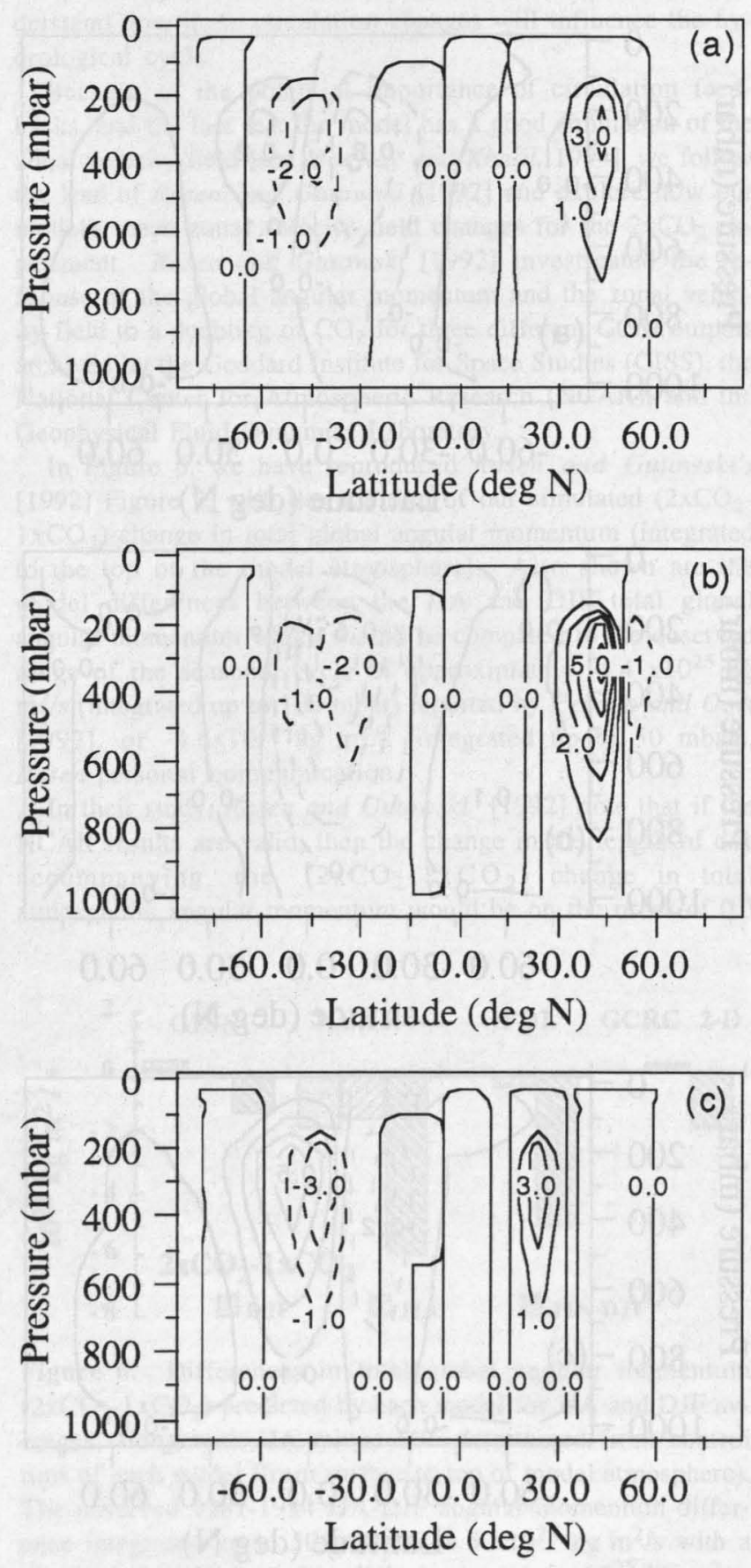

Figure 9. The simulated $\left(2 \mathrm{xCO}_{2}-1 \mathrm{xCO}_{2}\right)$ change in the zonal mean eddy momentum flux, $\overline{u^{\prime} v^{\prime}}$, for (a) annual, (b) JJA, and (c) DJF averages. Units are $\mathrm{m}^{2} / \mathrm{s}^{2}$, and contour interval is 1.0 . model is a direct consequence of the meridional temperature gradient changes.

This change in eddy momentum flux is also consistent with the changes in zonal velocity predicted by our model in Figure 7 and the increase in global mean kinetic energy described above. That is, the increase in $\overline{u^{\prime} v^{\prime}}$ flux in the midlatitude regions results in a greater transfer of westerly momentum out of the tropics and into higher latitudes. This results in an increase in the tropical easterly flow and a corresponding increase in high-latitude westerly flow. The change in eddy momentum flux does not explain the increase in westerly flow simulated by the model near the tropical tropopause. A similar pattern of change also exists for the GISS model (DJF and JJA) and the NCAR (DJF) model simulations examined by Rosen and Gutowski [1992]. In our model, this increase in westerly flow is a result of increased upper level meridional pressure gradients associated with the increased Hadley circulation discussed above. This results in strengthened geostrophic flow. Since, in general, our model's results are qualitatively consistent with the results of typical GCMs, we suspect that the same basic mechanisms operating in our model are responsible for first-order changes in mean zonal flow predicted by them.

The global mean annual precipitation estimated by our model increases by about $6 \%$ when atmospheric carbon dioxide is doubled. Mitchell [1989] compared the $\left(2 \mathrm{xCO}_{2}-1 \mathrm{xCO}_{2}\right)$ change in precipitation predicted by five GCMs. The percent changes in precipitation ranged from $+7.1 \%$ to $+15.0 \%$ for the five models reviewed by Mitchell. Although we have only made a first order estimate of precipitation in our model, the magnitude of change predicted by it is qualitatively consistent with other models. This increase in precipitation is direct consequence of the mass balance of water vapor in the model atmosphere; increased rates of evaporation due to higher surface temperatures result in increased condensation rates.

As a final comment on the climate sensitivity of the GCRC 2-D SDCM, the results presented here are all quite robust. Although the numerical values may change somewhat for changes in prescribed ozone profiles, surface albedo, cloud cover, etc., the qualitative features described here persist.

\section{Summary}

The sensitivity of the GCRC 2-D SDCM to the doubling of atmospheric carbon dioxide is investigated, and we find that the change in temperature structure predicted by the model has several features that are also common to GCMs. In particular (1) the annual mean warming is greatest at the poles and smallest at the equator, (2) there is cooling found in the stratosphere (which is also a characteristic of our 1-D RCM), (3) the warming at the poles is greatest during the winter months for the particular hemisphere, and (4) there is a local warming maximum predicted to occur in the middle to upper tropical troposphere. We have analyzed the response of our model by evaluating model diagnostics and performing experiments with the 1-D RCM component of the 2-D model. The above $\left(2 \mathrm{CO}_{2}-1 \times \mathrm{CO}_{2}\right)$ response characteristics are a result of complex interactions between radiation and dynamical effects. Several physical processes responsible for the above characteristics have been identified and discussed. Among these changes are differences in static stability, lapse rate feedback, changes in solar insolation reaching the surface, and changes in dynamical heat transport. 
Following the work of Rosen and Gutowski [1992], we investigated the change in zonal mean angular momentum and zonal velocity predicted by our model for a doubling of $\mathrm{CO}_{2}$. We find that our model simulates (1) an increase in easterly flow in the tropics, (2) an increase in westerly flow at midlatitudes, (3) an increase in westerly flow near the tropical tropopause, and (4) the net total angular momentum of the model atmosphere remains relatively unchanged, while the angular momentum of the troposphere decreases approximately $1.5 \%$ to $2 \%$.

With our model we are able to recognize patterns of change in the zonal velocity for the $2 \mathrm{xCO}_{2}$ experiment that are consistent with the change in temperature structure of the atmosphere. We suggest that the increase in upper level temperature gradients predicted by our model result in an increase in the simulated eddy flux of zonal momentum, $\overline{u^{\prime} v^{\prime}}$, and that this causes more westerly momentum to be transferred from the tropics to the higher latitudes. In addition, the very small change in total atmospheric angular momentum is due to the lack of orography in our model and the resultant weak coupling between the atmosphere and the solid earth. We also attribute the 3\% increase in global kinetic energy per unit area and the $5 \%$ increase in Hadley circulation to the enhanced upper level temperature-pressure gradients.

Our results clearly show that changes in the atmospheric concentration of trace gases such as carbon dioxide can influence the dynamics of the atmosphere. Additional work is required to understand exactly what climatic feedbacks will result from these changes in dynamics and to what extent these feedbacks may actually alter the climate system. We have suggested that two important possible feedbacks resulting from perturbations in atmospheric dynamics are changes in ozone distribution and changes in the hydrological cycle. To better understand these potential feedbacks, the next version of our model will include (1) a more realistic determination of the atmospheric moisture budget, including the prognostic development of clouds, (2) a physically based thermodynamic sea ice-snow cover model, and (3) greater vertical resolution near the tropopause and in the stratosphere.

Acknowledgments. We would like to thank Rei Rasmussen, Martha Shearer, Francis Moraes, Zhongyi Ye, and Yu Lu for their insightful discussions during the course of this work. We give special thanks to James A. Coakley Jr. for his thoughtful comments and suggestions during the early phases of this work. We would also like to thank an anonymous referee for their constructive comments on the initial manuscript. This work was partially supported by The U.S. Department of Energy grant \# DE-FG06-85ER60313, The Andarz Co., The Oregon Graduate Institute of Science \& Technology, and Clark College.

\section{References}

Branscome, L.E., and W. J. Gutowski, The impact of doubled $\mathrm{CO}_{2}$ on the energetics and hydrologic processes of midlatitude transient eddies. Clim. Dyn. 8, 29-37, 1992.

Held, I.M., and M.J. Suarez, A two-level primitive equation atmospheric model designed for climate sensitivity experiments. J. Atmos. Sci., 35, 206-229, 1978.

Held, I.M., Large-scale dynamics and global warming. Bull. of the Am. Meteorol. Soc., 74, 228-241, 1993.

Hunt, B.G., Zonally symmetric global general circulation models with and without the hydrologic cycle, Tellus 25, (4), 337-354, 1973.

Intergovernmental Panel on Climate Change, Climatic change, in The IPCC Scientific Assessment, edited by J.T. Houghton, G.J. Jenkins, and J.J. Ephraums. Cambridge Univ. Press, New York, 1990.

Lindzen, R.S., A.Y.Hou, and B.F. Farrell, The role of convective model choice in calculating the climate impact of doubling $\mathrm{CO}_{2}, J$. Atmos. Sci., 39, 1189-1205, 1982.

Liou, K.-N., An Introduction to Atmospheric Radiation, Academic Press, San Diego, Calif., 1980.
MacCracken, M. C., and S. Ghan, Design and use of zonally-averaged climate models, Rep. UCRL-94338, 44 pp., Univ. of Calif., Livermore CA, 1987.

MacKay, R.M., and M.A.K. Khalil, Theory and development of a onedimensional time-dependent radiative convective climate model. Chemosphere, 22, (3-4), 318-417, 1991.

MacKay, R.M., The Global Change Research Center 2-D statistical dynamical climate model. Ph.D. thesis, Oregon Grad. Inst. of Sci. \& Technol., Dep. of Environ. Sci. and Eng., Global Change Res. Center, Beaverton, Oreg., 1994.

MacKay, R.M., and M.A.K. Khalil, Climate simulations using the GCRC 2-D zonally averaged statistical dynamical climate model, Chemosphere, 29, (12), 2651-2683, 1994.

Manabe, S., and R.T. Wetherald, Thermal equilibrium of the atmosphere with a given distribution of relative humidity, J. Atmos. Sci., 24, (3), 241-259, 1967.

Mitchell, J.F.B., The "greenhouse" effect and climate change, Rev. of Geophys., 27, (1), 115-139, 1989.

North, G.R., R.F. Cahalan, and J.A. Coakley Jr., Energy balance climate models, Rev. of Geophys. and Space Phys., 19, 91-121, 1981.

Peixoto, J.P., and A.H. Oort, Physics of Climate, Am. Inst. of Phys., College Park, Md., 1992.

Ramanathan, V., Interactions between ice-albedo, lapse-rate and cloudtop feedbacks: An analysis of the nonlinear response of a GCM climate model, J. Atmos. Sci., 34, 1885-1897, 1977.

Ramanathan, V., and J.A. Coakley Jr., Climate modeling through radiative convective models. Rev. of Geophys. and Space Phys., 6, $465-489,1978$

Rosen, R. D., and W. J. Gutowski Jr., Response to zonal winds and atmospheric angular momentum to a doubling of $\mathrm{CO}_{2}, \mathrm{~J}$. of Clim., 5 , (12), 1391-1404, 1992.

Rosen, R.D., D.A. Salstein, and T.M. Wood, Discrepancies in the Earthatmosphere angular momentum budget, J. Geophys. Res., 95, (B1), 265-279, 1990.

Saltzman, B., and A.D. Vernekar, Global equilibrium solutions for the zonally averaged macroclimate, J. Geophys. Res., 77, (21), 39363945,1972

Saltzman, B., A survey of statistical-dynamical models of the terrestrial climate, in Adv. Geophys., 20, 1978.

Schlesinger, M.E., and J.F.B. Mitchell, Climate model simulations of the equilibrium climatic response to increased carbon dioxide. Rev. of Geophys., 25, (4), 760-798, 1987.

Schneider, E.K., and R.S. Lindzen, Axially symmetric steady-state models of the basic state for instability and climate studies, I, Linearized calculations, J. Atmos. Sci., 34, 263-279, 1977.

Schoeberl, M. R., and D. F. Strobel, The zonally averaged circulation of the middle atmosphere, J. Atmos. Sci., 35, 577-591, 1978.

Stephens, G.L., The parameterization of radiation for numerical weather prediction and climate models, Mon. Weather Rev., 112, 826-867, 1984.

Stone, P.H., and J.H. Carlson, Atmospheric lapse rate regimes and their parameterization, J. Atmos. Sci., 36, 415-423, 1979.

Stone, P.H., and M.S. Yao, Development of a two-dimensional zonally averaged statistical-dynamical model, II, The role of eddy momentum fluxes in the general circulation and their parameterization, J. Atmos. Sci., 44, (24), 3769-3786, 1987.

Stone, P.H., and M.S. Yao, Development of a two-dimensional zonally averaged statistical-dynamical model, III, The parameterization of eddy fluxes of heat and moisture, J. of Clim., 3, 726-740, 1990.

Wang, W.C., G. Molnar, M.K.W. KO, S. Goldenberg, and N.D. Sze, Atmospheric trace gases and global climate: A seasonal model study, Tellus, 42B, (2), 149-161, 1990.

Wetherald, R.T., and S. Manabe, The effects of changing the solar constant on the climate of a general circulation model, J. Atmos. Sci., 32, 2044-2059, 1975.

Yao, M.S., and P.H. Stone, Development of a two-dimensional zonally averaged statistical-dynamical model. I, The parameterization of moist convection and its role in the general circulation. J. Atmos. Sci., 44, 65-82, 1987.

M.A.K. Khalil, Oregon Graduate Institute of Science \& Technology, Global Change Research Center, Department of Environmental Science and Engineering, Beaverton, OR 97006. (e-mail: aslam@atmos.ogi.edu)

R.M. MacKay, Atmospheric and Environmental Research, Inc. 840 Memorial Dr., Cambridge, MA 02139. (e-mail: mac@aer.com)

(Received November 2, 1994; revised May 24, 1995;

accepted June 15, 1995.) 